\title{
Interpreting COVID-19 through the lens of the second Deep Transition
}

\author{
Is COVID-19 a stepping stone towards a more \\ sustainable future, or it is just a stone in the pond \\ of which the effects will wither away as soon as \\ we are back to normal? A look at the opportuni- \\ ties arising from the crisis. \\ By Johan Schot
}

W e know that COVID-19 is the worst global public health crisis in living memory. It is changing everyday life in an immediate and stark fashion across the world, arguably not seen since the Second World War. We are in self-isolation, need to stay at home, keep our distance from others, airplanes are grounded, public transportation is empty and home schooling is becoming the norm. But will this virus change how we live forever? Many are longing for a return to normal as soon as possible, while others are calling for the recovery period to be used to change our economies and societies to address the climate crisis. All of this begs the question: what does the COVID-19 crisis signify?

To answer this question and interpret the crisis we need a frame. In this article I am using the Deep Transitions framework to answer the question of the meaning of COVID-19 (Schot 2016; Schot/Kanger 2018; Kanger/Schot 2018; Swilling 2020), bringing to the fore deeper issues about whether we are living at a tipping point in history, a divide between what I will call a First and Second Deep Transition, and are experiencing a period in which the world is making a significant move towards a more sustainable future?

\section{A shock for the socio-technical landscape}

In the Deep Transitions framework COVID-19 is a shock produced at the landscape level. The landscape is our social, technical and ecological environment which surrounds and sustains us. The landscape is our context which we cannot easily influence, at least not in the short-term. We can take measures to combat COVID-19 and reduce the probability of new pandemics emerging, yet our modern societies will continue to cause them to occur; they are a normal accident (Perrow 1984), one that is expected and caused by how we organize our societies and economies. The landscape consists of many trends: urbanization, climate change, rising inequality, individualization, digital transformation, hyper-modernity and globalization are all developments within it. Landscape trends put pressures on the way we live and we have to adapt to them. They can also produce shocks. Such shocks appear as if they have been produced suddenly, but have been building up as a result of the synergies between all trends, as volcanos and earthquakes suddenly erupt and generate havoc.

Our modern landscape is not a natural one, it is a socio-technical landscape in which nature has been transformed by human beings in an unprecedented way. This is the idea behind the proclamation we live in the Anthropocene (Crutzen 2002). Humans have used science and technology to build a complete new world, a new life-style based on abundance. Now we have to live with the ecological consequences, such as the climate and biodiversity crises, and the social consequences, the uneven distribution of abundance. These consequences are embedded in the deep choices we have made when designing this world, which suggests that we cannot fix the consequences by small adjustments. This world was created during the first Deep Transition that started at some point in the $18^{\text {th }}$ century. Historians refer to it as the Industrial Revolution. I prefer to use the notion of Deep Transition because it expresses better the underlying dynamics. Industry becoming a driver for change is certainly pivotal, but the genesis of the modern world should be located in implementing a number of new sociotechnical systems for the provision of basic needs: energy, mobility, healthcare, water, communication, food, housing, that were optimized in specific directions. The use of fossil fuels, linear production using nature as a free sink, labour productivity instead of land or resource productivity, globalized and industrial production, mass production and mass consumption. In this way industrialization is one of the directions, among others.

In the Deep Transitions framework these directions are a result of the adoption of meta-rules by a wide range of actors from business, to governments, to citizens and consumers and social movements, who use these rules to create, maintain and improve the energy, water, mobility, housing, food and other systems. The meta-rules for the governance of these systems have been framed by the struggle between communism, fascism and democracy often tied to capitalism, and the acceptance of technocracy across all three ideologies. Capitalism has become dominant and promotes the idea that the market should put the systems in place, run them, and in this process generate economic growth, while the state is responsible for fixing market failures, and managing the consequences through regulation, putting limits on how the market operates. 


\section{"COVID-19 will help \\ to promote specific niches \\ and help to de-stabilize \\ some existing systems. "}

\section{Opportunities for Deep Transitions?}

A Deep Transition can thus be defined as a series of connected fundamental transformations of a wide range of sociotechnical systems in a similar set of directions. We use the word deep because it is about a broad set of systems providing our society with a socio-technical landscape as we know it today, but also because it has been created through interactions of many actors who have put in place a new set of meta-rules that govern their behaviour, beliefs and values. When a set of rules are aligned it is called a regime. The notion of rules occupies a central place in institutional theory (Giddens 1984) as well as in institutional economics (North 1990). Rules are institutions setting constraints on specific action while making other actions possible. Rules are difficult to change, not only because they are collective, but also because they are embedded or expressed in systems. Individuals or organizations may want to have a sustainable lifestyle or operation, but they are often constrained by other actors, the systems put in place, and ultimately the landscape in which they act.

Taking the Deep Transition framing into account, how does change come about? It starts in specific environments which protect actors against the behaviour of dominant system actors, and against many trends at the landscape level that are aligned with rules used for running the systems. Building on sustainability transitions thinking, these environments are called niches (Grin et al. 2010). This is how solar and wind energy came into being. They were nurtured in niches. They began as a new practice of decentralized energy production, establishing new user preferences, new regulatory measures and infrastructural changes. The niches were protected by subsidies and/or strong collectives accepting the constraints. The landscapes are not only supporting the dominant systems, some trends may also help to induce niche development. A landscape trend and shocks such as climate change contributed to the development of renewable energy niches. Within the niche actors engaged in learning, networking, and visioning leading to the buildup of a new socio-technical energy system, which then began to compete head on with the centralized electricity production system based on fossil fuels. Change does not only come about through niche development, it also needs a destabilization of the dominant systems; this can happen because of the threat of a new competitor, but more often systems themselves are hollowed out because actors supporting them start to question the ability of systems to resolve the problems as they appear within the landscape, and are voiced by a range of actors, often by social movements in the first instance (Kivimaa \& Kern 2016).

This dynamic of niche and system (or regime) competition influenced by landscape development operates within areas such as energy, mobility, food single systems, but also across systems because they are coupled through global value chains, sharing of resources (for example research infrastructures) and exchanging of experiences, so actors in each system learn from one other. It is this process in which niches and systems become aligned that a transition is deepened because niches and systems begin to operate according to a similar set of rules. These rules act as the genotype of further evolution. Mass production was not a dominant practice for many systems, as a set of principles it was only used in a number of niches (mainly the car industry), and it was highly contested before the Second World War. After the War the principles of mass production and the factory became a dominant practice for food production, agriculture, construction, and healthcare for example.

For new systems to emerge and become established dominant practice it may take 40 to 60 years. Perez (2002) calls this a Surge of Development. Each surge has a turning point somewhere in the middle, whereby actors are forced by a huge crisis to decide on the directionality of the surge, or in other words, the competition between various niches and systems. For the Fourth Surge the Second World War gave the final push to mass production and mass consumption becoming the dominant meta-rule sets for many systems (see figure 1).

\section{A pandemic of change?}

What does this all imply for our interpretation of COVID-19? This pandemic comes at a time of a turning point of the Fifth Surge fueled by the meta-rules of digitalization influencing many systems, but not in a decisive way. This is also a Surge in which many systems are questioned because of the ecological and social consequences they have generated. A wide range of actors have called for a wider transformation. This is indeed why the United Nations Sustainable Development Goals are important. These are goals accepted by almost all nations of the world for transforming our world and our systems. To therefore take digitalization forward, it needs to be married to other social and ecological meta-rules. The world is not only questioning the dominant practices and systems, at this point in time meta-rules are nurtured in niches. They exist and thrive there. Examples are organic and localized food production, the retrofitting of houses, renewable energy, new forms of water provision that reduce the need for fresh water, a focus on pre- 
vention and lifestyle changes in medical care. The big question is thus whether the actors will decide to build a Fifth Surge towards a digital future in which these niches are incorporated without changing a major directionality, so green and social issues are secondary drivers (meta-rules). This may result in green growth with a very uneven global distribution of the benefits and impacts however. The alternative is actors investing in building up the Second Deep Transition, niches becoming the lever for creating a new development pathway diverting from the Industrial Modern Society as we know it today (see figure 1). Such a pathway is putting the double ecolog-

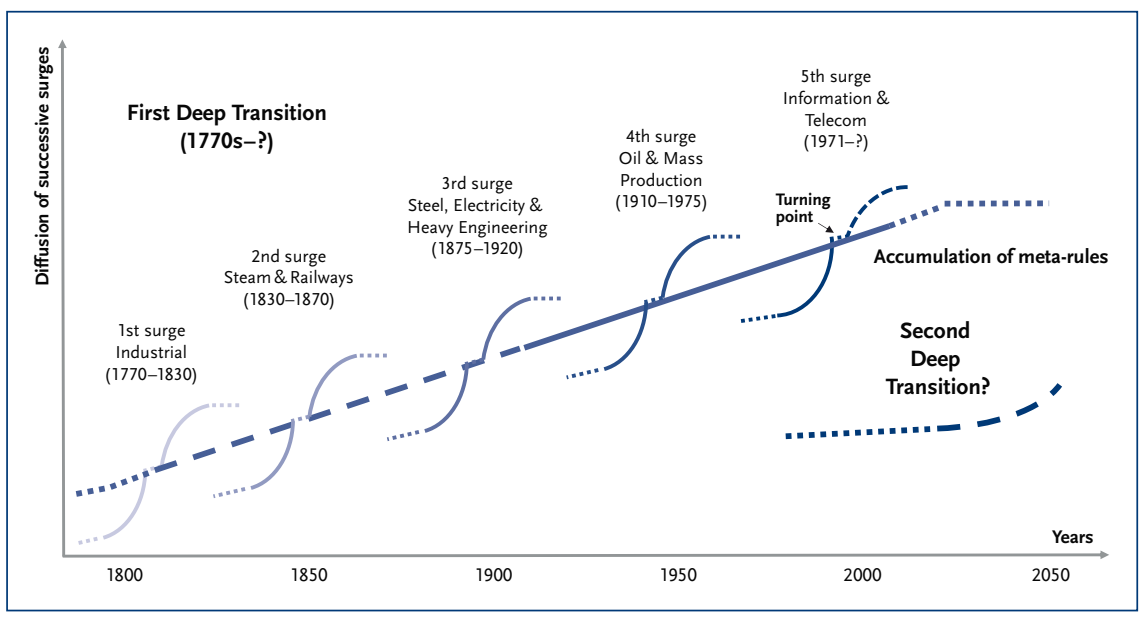

Figure 1: First and Second Deep Transition (drawn by Laur Kanger). An adapted version can be found in Schot and Kanger 2018, p. 1055. ical and social challenges at the heart of the development paradigm. Growth and progress will be measured in completely new ways. This is not a binary choice, both may happen simultaneously, and blends are conceivable, however at some point one will become the dominant development pathway. When this will happen is the fundamental question.

COVID-19 as a landscape shock can play a role in both scenarios. It will not single-handily trigger a big change itself, however it will be a factor in the battle between prolonging the First Deep Transition and building up the Second Deep Transition. Most likely it will help to promote specific niches, and help to de-stabilize some existing systems (healthcare, food, mobility systems) because actors have been convinced that COVID-19 should not be treated as a normal accident, but as a signifier of a bigger set of crises that require addressing. Whether this happens in reality and with what impacts can only be documented in retrospect, however COVID-19 has clarified once again that the need for a Second Deep Transition should be embraced in order to avoid further regional and global lock-downs as a result of future social and ecological crisis in the coming decades, let alone the prospects of New Wars that may be caused (Johnstone \& MacLeish 2020 a and 2020 b).

\section{References}

Crutzen, P. J. (2002): Geology of mankind. In: Nature 415: 23.

Giddens, A. (1984): The Constitution of Society. Berkeley, University of California Press.

Grin, J./Rotmans, J./Schot, J. W. (2010): Transitions to Sustainable Development: New Directions in the Study of Long Term Transformative Change. New York, Routledge.

Johnstone, P./McLeish, C. (2020a): The Role of War in Deep Transitions: Exploring Mechanisms, Imprints and Rules in Sociotechnical Systems. https://deeptransitions.net/publication/the-role-of-war-in-deeptransitions-exploring-mechanisms-imprints-and-rules-in-sociotechnicalsystems/

Johnstone, P./McLeish, C. (2020 b): The 'COVID war'? Reflections on mechanisms and the imprints of the COVID-19 pandemic. https://deeptransitions.net/publication/the-covid-war-reflections-onmechanisms-and-imprints-of-the-covid-19-pandemic/

Kanger, L./Schot, J.W. (2019): Deep transitions: Theorizing the long-term patterns of socio-technical change. In: Environmental Innovation and Societal Transitions 32: 7-21.

Kivimaa, P./Kern, F. (2016): Creative destruction or mere niche support? Innovation policy mixes for sustainability transitions. In: Research Policy 45/1: 205-217.

North, D. (1990): Institutions, Institutional Change and Economic Performance. Cambridge, Cambridge University Press.

Perez, C. (2002): Technological Revolutions and Financial Capital. Cheltenham, Edward Elgar Publishing.

Perrow, C. (1984): Normal accidents: Living with high-risk technologies. New York, Basic Books.

Schot, J.W. (2016): Confronting the second deep transition through the historical imagination. In: Technology and Culture 57/2: 445-456.

Schot, J.W./Kanger, L. (2018): Deep transitions: Emergence, acceleration, stabilization and directionality. In: Research Policy 47/6: 1045-1059.

Swilling, M. (2020): The Age of Sustainability, Just Transitions in a Complex World. London, Routledge.

\section{AUTHOR + CONTACT}

Johan Schot is Professor at Utrecht University Centre for Global Challenges, The Netherlands \& Visiting Professor at University of Johannesburg, South Africa. $\mathrm{He}$ is also Academic Director of the Transformative Innovation Policy Consortium.

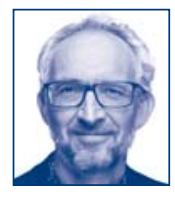

Utrecht University, Centre for Global Challenges, Janskerkhof 2-3 a, 3512 BK Utrecht. Tel.: +31 302538470 , E-Mail: j.w.schot@uu.nl 